\title{
Retolació ceràmica urbana dels segles XVIII i XIX: les fàbriques de València
}

\section{Urban ceramic lettering of the 18th and 19th centuries: the factories of València}

\author{
Beatriu Navarro i Buenaventura \& Josep Lluís Cebrián i Molina \\ beatriu.navarro@gmail.com / josep.lluis.cebrian@uv.es
}

Universitat de València

Resum: Les ciutats començaren a retolar amb taulells els noms dels carrers i dels edificis públics, $i$ a numerar les cases, en compliment de la Cèdula reial de 1769 promulgada per Carles III. En aquest article estudiem l'evolució de la retolació urbana al llarg dels segles XVIII i XIX. A partir de diversos casos documentats -Xàtiva, Sogorb, València, Ciutat de Mallorca- i dels taulells i plaques ceràmiques conservats, analitzem aquesta vessant de la taulelleria valenciana.

Paraules clau: taulelleria, toponímia urbana, segle XVIII, segle XIX, València

\begin{abstract}
The cities began to signal the names of streets and public buildings with tiles, and to number the houses, in accordance with the Royal Decree of 1769 promulgated by Carles III. In this paper we study the evolution of urban signage throughout the 18th and 19th centuries. Based on documented examples -Xàtiva, Sogorb, Valencia, Ciutat de Mallorca- and the preserved ceramic tiles and plates, we analyze this aspect of Valencian tilework.
\end{abstract}

Keywords: glazed tiles, urban toponymy, 18th century, 19th century, València 
Beatriu Navarro i Buenaventura \& Josep Lluís Cebrián i Molina. Retolació ceràmica urbana del segles XVIII i XIX: Les fàbriques de València

Entre les diverses tipologies produïdes en la taulelleria valenciana dels segles XVIII i XIX destaquen els plafons devocionals, als quals hem d'afegir els viacrucis, els revestiments de cuina, els paviments, les socolades, els quadres, els brancals o les làpides funeràries. Les plaques administratives o de retolació urbana, si bé en ocasions apareixen recollides en catàlegs i inventaris, manquen en certa manera d'una sistematització o d'un estudi general de conjunt, sobretot des del punt de vista historicoartístic. Als treballs més recents sobre taulelleria valenciana, on s'han redefinit els paràmetres de classificació tipològica, el rètols s'han inclòs dins del grup de la pintura ceràmica, per tractar-se d'obres realitzades ad hoc, al contrari que taulelleria de mostra (Gironés \& Guerola 2016: 35). Però el fet que les retolacions manquen majoritàriament d'elements figuratius o escenes narratives - no sempre, com veurem- ha provocat potser una certa relegació a l'hora d'abordar un estudi en profunditat.

Les seues característiques han provocat que siguen susceptibles de desaparèixer de la via pública per causa del creixement urbanístic, l'especulació, l'abandonament de nuclis urbans, els canvis de denominació dels carrers, la demolició d'edificis antics, el comerç d'antiguitats, o la pèrdua de la seua funció viària. La transformació del paisatge urbà ha comportat en nombroses ocasions el canvi de lloc i, per tant, la descontextualització d'aquests rètols situats als carrers. Bastants, per sort, encara es conserven in situ -formant part d'un grup ceràmic heterogeni acumulat al llarg dels anys-, i d'altres han estat recuperats per les administracions públiques i formen part de les seues col leccions o s'exposen als museus.

\section{Rètols de carrer al segle XVIII}

Va ser al segle XVIII, a partir de les disposicions il lustrades de Carles III, quan començaren a retolar els noms de places i carrers, a més de numerar les illes d'edificis i les cases. La finalitat de la normativa era cadastral i tributària al temps que uniformadora de les principals ciutats de la monarquia. Els taulells eren un recurs durador i elegant per aconseguir-ho, a més que milloraven l'aspecte urbà.

Especialment ens interessa, pel que fa a la retolació dels carrers, la Cèdula reial del 13 d'agost de 1769 estableciendo alcaldes de quartel y de barrio en todas las ciudades donde residen chancillerías, y audiencias reales, con derogación de fueros, y demás que expresa. Ciutats entre les quals s'inclou València En l'apartat XIII de la cèdula legim textualment:

Todas las casas de las referidas ciudades, inclusas Parroquias, Conventos, Iglesias, y Lugares píos se numerarán con azulejos, como también las Casas de Ayuntamiento, y las de las Chancillerías, y Audiencias, sin exceptuar alguna, por privilegiada que sea, distinguiendolas en Manzana, como se ha hecho en Madrid, y á costa de sus dueños. ${ }^{1}$

1 Abans s'havia publicat la C. R. de 6 d'octubre de 1768 referida a Madrid. 
Beatriu Navarro i Buenaventura \& Josep Lluís Cebrián i Molina. Retolació ceràmica urbana del segles XVIII i XIX: Les fàbriques de València

Una de les primeres ciutats valencianes on s'ha documentat la col locació de taulells és Xàtiva (Cebrián \& Navarro, 2009: 163). L'any 1788 el regidor Tomàs Roca proposà situar als cantons de cada carrer un taulell amb el nom, perquè quan la tropa arribava a la ciutat no trobava l'allotjament i els veïns desconeixien els noms. La nomenclatura, com en la majoria de ciutats i pobles, es basava en la tradició o costum popular, de manera que era inconstant, i per tant calia fer-la oficial i unívoca.

Segurament fruit d'aquella proposta són alguns taulells quadrats d'aproximadament $20 \mathrm{~cm}$. de costat que conserva la ciutat. Combinen lletres blaves sobre fons blanc amb un marc pintat en verd turquesa i perfilat en manganès. La cal ligrafia fa servir majúscules i minúscules i presenta un punt final.

L'any 2008, quan catalogàrem la taulelleria de Xàtiva, encara hi havia al lloc original rètols amb aquest disseny, com la Plaza de la Seo [fig. 1], vora el cantó esquerre de la façana principal de l'Hospital Vell, la Calle y Plaza de Peris, l'Obra Nueva al mur lateral de l'Apotecaria d'Artigues (davant del campanar), la Plaza de Bonaire o la Calle de $S^{n}$ Joaquín. També trobem taulells de numeració amb la paraula Casa dalt del dígit corresponent, com el de la Casa I del carrer del Pes, vora el de la Corretgeria. Recentment, alguns han estat retirats de la via pública.

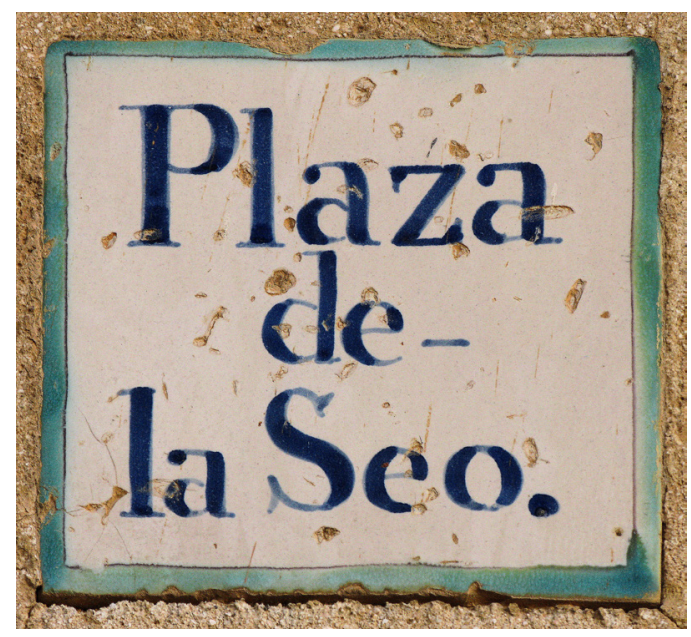

Fig 1. Plaça de la Seu, Xàtiva

El disseny i la qualitat dels taulells ens remeten a la fàbrica del carrer Mossèn Femades de València que dirigia el xativí Marc Antoni Disdier. Molt possiblement la proposta de retolació de la toponímia urbana realitzada pel regidor Roca en 1788 està lligada al subministrament de taulells per a l'Hospital de Xàtiva que eixe mateix any havia fet el fabricant Disdier, el qual a més havia estat administrador de la institució sanitària en 1772. Està documentada l’adquisició entre maig i juny de més de 1.600 taulells de mostra, de cortapisa o sanefa i de números de llit per a la sala nova de les dones (Cebrián \& Navarro, 2009: 150). La socolada amb els taulells de mostra esmentats es pot veure a l'escala de l'edifici. Respecte als tableros de número de llit cal remarcar les analogies que mostren amb els rètols 
Beatriu Navarro i Buenaventura \& Josep Lluís Cebrián i Molina. Retolació ceràmica urbana del segles XVIII i XIX: Les fàbriques de València

que estudiem, especialment pel color blau de l'escriptura i el marge exterior turquesa, encara que combinat amb vores de color groc i ocre.

Justament a Cocentaina podem veure taulells del mateix estil on s'ha fet servir el color ocre per a vorejar la peça, en aquest cas sense perfilat de manganès, i el blau per a les lletres també. L'esmalt blanc del fons en canvi no té la qualitat dels anteriors, ja que presenta alguns defectes de cuita com clivelles i bombolles. En trobem per exemple a la PLAZA DEL SALVADOR, tot en lletres majúscules, o a la Calle Salida para Fraga, en minúscula, i diverses de numeració de casa. Tot fa suposar l'origen en una fâbrica diferent.

De cronologia posterior, els taulells de nomenclatura de Sogorb deuen tenir idèntica procedència fabril que els de Xàtiva. Les dimensions són igual i segueixen el mateix patró, amb lletres rodones minúscules encapçalades per capital i punt final, i marge turquesa perfilat amb manganès. La cal ligrafia ha canviat lleugerament $i$ ara les lletres són de color negre. Afortunadament contenen la datació en la part inferior, on llegim l'any 1804 en què foren pintats.

Allò que particularitza la retolació de Sogorb, a més de la valuosa informació cronològica que ens proporciona, és el propòsit d'embelliment urbà. Sobre el taulell identificador, n'obraren un altre amb les mateixes dimensions on s'hi representa un personatge o objecte. Encara es poden veure in situ els noms de Calle de $S^{\text {ta }}$ Maria, Calle del Cereso. Año 1804 [fig. 2] i la Calle de $S^{n}$ Vicente 1804. Els dos primers mostren respectivament un caçador amb l'arma al muscle i una dona amb cistell al cap. Pintats per mans diferents, ambdós tenen una composició senzilla i elegant. Situen la figura, dibuixada amb perfilat fi, sobre un petit monticle amb vegetació baixa, tot resolt a base de pinzellada ràpida.

Es tracta de peces conegudes com taulell de dibuix complet o taulell de figura que generalment s'obraven al murs de les cuines amb funció higiènica alhora que estètica i dels quals el Museu de Belles Arts de Castelló exposa un repertori variat (Olucha, 2020: 112-115). Encara resten cuines amb conjunts de xapats originals com a la Casa del Bisbe

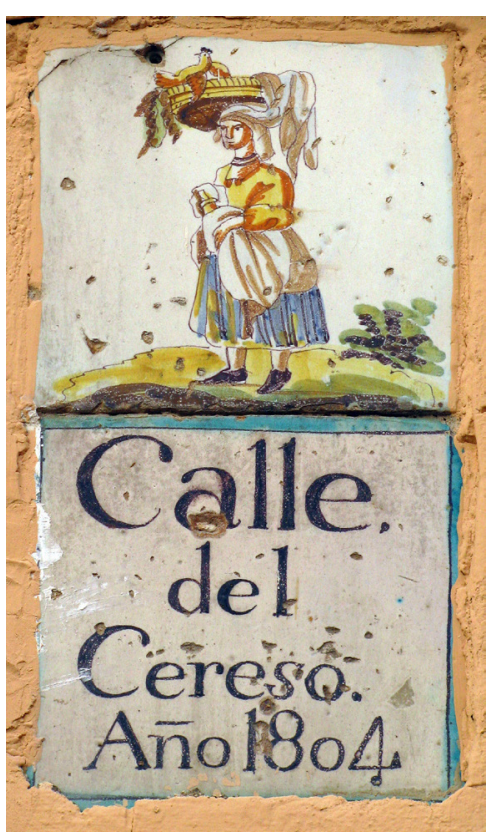

Fig 2. Carrer del Cerezo, Segorb Bertran de la Serra d'En Garcerà o la Casa d'Alòs a Alzira.

Generalment la font gràfica en la qual es basaven les representacions eren gravats amb figures humanes, atifells de cuina, aliments, animals, etc. que compilaven a les fàbriques on s'elaboraven els taulells (Gironés \& Guerola, 2016: 40-42, 289 i ss.). 
Beatriu Navarro i Buenaventura \& Josep Lluís Cebrián i Molina. Retolació ceràmica urbana del segles XVIII i XIX: Les fàbriques de València

Relacionada amb el disseny de Xàtiva i Sogorb cal esmentar una mostra poc freqüent en terres valencianes de retolació devocional localitzada a Quart de Poblet, a l'atzucat de la Plaça de Valldecabres. Presidint la porta d'accés d'una casa llegim sobre taulells de format rectangular a manera de sanefa ALABADO SEA EL SS. SACRAM. DEL ALTAR PARA SIEMPRE ALABADO SEA. La frase inclou la invocació i la resposta, dins del culte al Santíssim fomentat durant els segles XVII i XVIII. Sobre la llegenda hi ha un taulell que conté la data: AÑO 1805 (Cebrián, 2005: 99). Presenta una vora turquesa perfilada amb morat de manganès i està tot escrit en majúscules negres. La cronologia propera als anteriors, el model de taulell vorejat i la perfecció cal ligràfica indiquen que es tracta d'un producte eixit de la Reial Fàbrica de València. Es constata així que la fàbrica dels Disdier emprà, durant els últims anys del segle XVIII i principis del XIX, la motlura turquesa per a embellir certes obres que havien de contenir una inscripció.

A l'últim decenni del set-cents l'Ajuntament de Ciutat de Mallorca decidí retolar els seus carrers (Zaforteza, 1956). Reunit el Capítol en sessió el 29 de juliol de 1794 s'exposava l'interès d'obrar taulells en les cases tal i com s'havia fet a València $i$ altres ciutats en compliment de la cèdula reial del 1769. Amb aquest propòsit demanaren a la fàbrica que Josep Cola tenia al carrer de les Barques de València unes mostres de taulells per a número de casa, per a illa de cases i per a nom de carrer, amb els preus corresponents. Per la resposta sabem que tots els taulells són iguals, amiden 1 pam castellà i costen cadascun 1 sou, i que també n'hi ha rajola petita a 4 diners. No s'arribà, però, a un acord amb Josep Cola. Suposem que per causa del retard de l'Ajuntament en enllestir la relació de carrers, illes i cases de la ciutat.

Al cap d'un any, el 20 de juliol de 1795 Marc Antoni Disdier també envià les mostres i els preus. En la carta que remet informa que el preu és de 2 sous -just el doble que els taulells de Cola-, i explica que a la seua fàbrica es fa el millor producte. De manera que si l'Ajuntament vol encomanar-li els taulells ha d'enviar el llistat de tots els números de casa i illa, noms de carrer «y demás que gusten para govierno». A més, fa una advertència important $i$ és que els han de donar temps per a fabricarlos perquè hi ha molt pocs oficials que saben fer la lletra amb tanta perfecció. Per acabar adverteix que es pot substituir el color blau de les lletres dels rètols per negre si ho prefereixen.

L'Ajuntament decideix finalment que la retolació dels carrers de la ciutat la farà Tomàs de Dussueil, un fabricant francés de València, qui oferia preus més baixos. Els taulells arriben a Palma en abril de 1796 i en 1797 estan col locats. Posteriorment, el 1862 es creà una comissió per a estudiar la substitució dels noms de carrer.

Entenem que els taulells de mostra que Disdier expedí des de València a Ciutat de Mallorca serien similars als que hem vist als carrers de Xàtiva -amb lletres blaves- i a Sogorb -de cronologia posterior i amb lletres negres-. Era evident la qualitat tècnica i artística dels productes de les Reials Fàbriques de Disdier, molt lluny dels taulells que finalment s'obraren als carrers de Palma. S'han conservat algunes retolacions de Mallorca, en l'elaboració de les quals calgué usar plantilles per a 
Beatriu Navarro i Buenaventura \& Josep Lluís Cebrián i Molina. Retolació ceràmica urbana del segles XVIII i XIX: Les fàbriques de València

les lletres per solucionar la manca de destresa dels pintors. ${ }^{2}$ De fet, l'encarregat de fer les gestions a València, en la carta tramesa a l'Ajuntament ja va advertir que Disdier era el «fabricante de la mejor fábrica de azulejos que ay en esta ciudad» i que encara que hi ha altres fàbriques que poden oferir el producte sol licitat «no seran del vernís tan fino como los de esta fábrica».

\section{Rètols de carrer al segle XIX. Canvi de format i d'estil}

Segons s'esmenta en la documentació de l'Ajuntament de Ciutat de Mallorca, València ja tenia instal lada la retolació l'any 1794. En efecte, ràpidament, en octubre de 1769 es procedí a la divisió administrativa i territorial de la ciutat segons s'ordenava a la cèdula reial (Madoz, 1849: 372). D'aquell moment, encara resten senyalitzacions als carrers de València, com la de MANZANA 327 vora la Llotja (Mateo 1998: 16, 41, 48, 64, 78), molt semblants als que hem vist a Palma.

Ens informa Madoz al seu Diccionario que a València hi havia intramurs 6.345 cases, repartides en 417 illes, 431 carrers i 132 places; «numeradas las primeras y segundas con buenos azulejos, y renovados recientemente los nombres de las localidades, en azulejos también, con buenas letras y claras» (Madoz, 1849: 372).

La renovació referida per Madoz deu ser la que es dugué a terme en 1837 amb taulells de la fâbrica de Ramon Sanchis, situada al carrer de Mossèn Femades, que anys abans havia estat propietat dels Disdier. Dues obres conservades al Museu de Sèvres certifiquen que Sanchis seguia usant la marca prestigiosa de l'empresa.

Es tracta d'un parell de plafons de 1836 -Conquesta de València per Jaume I i Paella a la Devesa del Saler-pintats per l'anomenat Pintor de la Conquesta, que foren adquirits pel baró Isidore Taylor i donats posteriorment al museu. ${ }^{3}$ De format apaïsat, estan compostos per 54 taulells cadascun amb un marc classicista integrat. A la part inferior dreta apareix el lloc de producció i l'any: De la RlFca de azulejos de Valencia. Año 1836. Són les dues úniques obres conegudes del període que tenen la marca de la fabrica, la qual cosa significa que la direcció les considerava dignes de representar la gamma alta de la producció (Cebrián 2014).

Pel que fa a la retolació dels carrers valencians de 1837, és el propi Ramon Sanchis qui ho manifesta en un escrit que remet en 1841 a la Comissió d'Indústria i Arts de la Societat Econòmica d'Amics del País de València on esmenta els avenços tècnics aconseguits a la fàbrica de la seua propietat. Declara que ha elaborat una multitud de taulells de numeració per a la ciutat pintats amb un color negre el secret del qual ningú no posseeix. ${ }^{4}$

\footnotetext{
2 Imatges d'aquells taulells es poden veure a l'article esmentat de Zaforteza (1956: lam. I i II) on documenta el procés o al llibre de Cabot i Mulet (1990: 27).

3 El baró i el pintor Adrien Dauzats feren una expedició a Espanya entre 1835 i 1837 per tal d'adquirir pintura per a la col lecció del rei francés Louis-Philippe.

4 RSEAPV. 25 nov. 1841. Ramón Sanchis manifiesta los progresos técnicos logrados en la fábrica de azulejos bajo su dirección. En línia http://hdl.handle.net/10251/21688.
} 
Beatriu Navarro i Buenaventura \& Josep Lluís Cebrián i Molina. Retolació ceràmica urbana del segles XVIII i XIX: Les fàbriques de València

D'aquestes paraules de Sanchis cal destacar el color negre, que efectivament és molt obscur i compacte. Un pigment, que a més d'usar en altres obres com els plafons devocionals, és altament adequat per a millorar la visibilitat dels rètols. És de suposar que aquestes inscripcions compostes en negre sobre fons blanc requerien una preparació especial dels òxids que encaria el producte respecte a les blaves tradicionals que encara s'hi feien.

Moltes de les plaques de retolació que es coïen ara als forns de la ciutat de València havien adoptat el model de Sanchis. S'utilitzaven les lletres capitals en tota la inscripció, clarament inspirades en caràcters tipogràfics, per tal de facilitar la lectura als vianants, i els taulells de nomenclatura s'havien substituit per plaques rectangulars de major grandària.

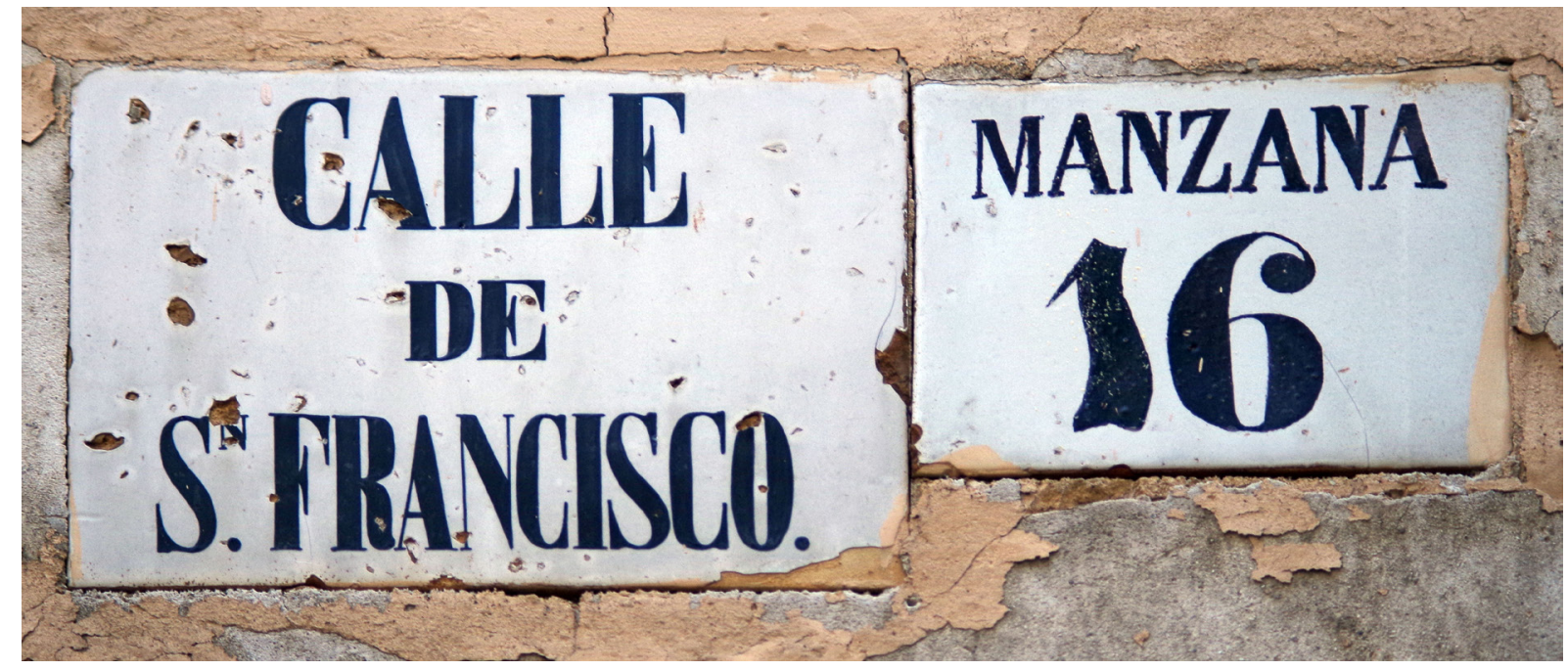

Fig 3. Carrer de San Francisco i Manzana, 16, Segorb

El fabricant Rafael González Valls presentà, entre altres obres costumistes, unes plaques amb propaganda de la seua factoria a l'Exposició Universal celebrada a Londres el 1851. Es conserven al Museu Victoria and Albert de la ciutat formant part d'un panell on es veuen taulells de dibuix complet amb aus i fruiters, a més de la placa central amb el nom del propietari (Ray 2000: 391-392). A les plaques de retolació s’hi llegeix CALLE DE CUARTE i No 10 , en majúscules i negre. ${ }^{5}$

Són idèntiques a les que trobem als carrers de Sogorb. En 1853, passats dos anys de l'exposició de Londres, l'Ajuntament de la ciutat encarregà a González Valls la nova retolació, després d’haver estudiat les mostres enviades i concretat el pressupost (Faus 1983: 33-36). Els caràcters de la preposició DE situada al centre, igual que en la placa de Londres, són menors que la resta. Observant amb deteniment les plaques s'aprecia però una mínima oscil lació en les dimensions de les lletres i en l'espaiat entre elles. Fins i tot es detecten variacions en la cal ligrafia. Tot produit segurament perquè el nom del carrer no es pintà per la mateixa mà que féu les inscripcions genèriques de Calle,

5 Imatge en http://collections.vam.ac.uk/item/O162431/tile-panel-unknown/ 
Beatriu Navarro i Buenaventura \& Josep Lluís Cebrián i Molina. Retolació ceràmica urbana del segles XVIII i XIX: Les fàbriques de València

Plazuela, Manzana... i per a les quals hi hauria estergits i plantilles. Es poden veure diverses mostres in situ a CALLE DE AUGUSTO, CALLE DE SAN FRANCISCO [fig. 3], PLAZA DE LAS MONJAS, PLAZUELA DE LA SANGRE O CALLE DE CEBRIAN.

Molt possiblement la instal lació del panell amb indulgències en una façana a la Plaça del Agua Limpia de Sogorb estiga directament relacionada amb la comanda de les noves senyalitzacions urbanes a González Valls, tant per la cronologia com per estil. Està compost per nou taulells, tot orlat amb una línea blava, amb la següent llegenda:

D. Fr. DOMINGO CANUBIO Y ALBERTO / OBISPO DE SEGORBE, / concedió cuarenta dias de indulgencia á todos / los fieles que devotamente rezaren ante esta Ima- / gen, una Ave Maria, Salve, Bendita sea tu pureza. / Letania lauretana; ó descubriendose los hombres / la cabeza o las mugenes inclinandola dijeren / Ave Maria Purisima, rogando por la exalta- / ción de la santa fé católica i demas fines pia- / dosos de muestra santa madre iglesia; y asi- / mismo por encomendarse á ella en cualquiera / aflicion / AÑO 1854.

Les indulgències estan just a la vora del plafó devocional dedicat pels veïns a la Mare de Déu del Lloret signat per Pasqual Rosselló uns anys abans, el 1847. El pintor, que havia estat alumne de Josep Sanchis i Cambra, dirigí la fàbrica de González Valls on es va coure el plafó (Cebrián \& Navarro 2014: 30-31). En la part central inferior de la sanefa que l'envolta hi ha un taulell de vora blava amb l'escut del bisbe. Potser aquest taulell, d'estètica diferent, fou afegit posteriorment, quan s'obraren al costat les indulgències del bisbe, procedent també de la fàbrica de González Valls si atenem a la cal ligrafia, amb la $\mathrm{R}$ i la $\mathrm{G}$ tan singulars.

La imprecisió esmentada en la configuració cal ligràfica de les plaques de retolació de Sogorb contrasta amb l'acuradíssim treball dut a terme en les noves retolacions de Xàtiva de 1861. A la capital de la Costera s'instal laren rètols ceràmics d'una placa, més grans i massissos que els anteriors de 1788 i en format rectangular, d'uns 28 x $35 \mathrm{~cm}$. La cal ligrafia, perfectament modulada amb caràcters negres sobre fons blanc, conjuga molt pulcrament els traços gruixuts amb els prims, amb uns remats molt subtils. Totes les lletres tenen idèntiques dimensions i les línies que les configuren són totalment paral leles entre elles.

Gran part d'aquests rètols de meitat del segle XIX romanien in situ al nucli antic fins fa poc. CALLE DE LA NEVATERIA VIEJA [fig. 4], CALLE DE FUENTE ALTA, CALLE DE VENTRES, CALLE Y PLAZA DE AUGER, CALLE DE CEBRIAN, són algunes de les nombroses plaques que es col locaren. Són peces encarregades per l'Ajuntament de Xàtiva a la fàbrica de Vicent Sanchis de València, segons llegim al llibre d'actes de 1861 (Cebrián \& Navarro 2009: 164-168). En setembre d'eixe any la comissió encarregada nomenà els senyors Ridocci i Pastor per a que:

Debiendo llevarse a efecto en cumplimiento de lo dispuesto por la superioridad, la numeración de las manzanas que forman las casas de esta ciudad y la variación de los rótulos de las calles y plazas, reportaran antecedentes sobre el precio de los azulejos necesarios para ambas reformas. Passats dos mesos, l'11 de desembre s'admeten les proposicions per a facilitar els taulells de 
retolació dels carrers, places i numeració de nínxols del cementeri:

Vistas las proposiciones presentadas por varios fabricantes de azulejos, relativas a la confección de los que se necesitaban en esta ciudad para renovar los rótulos de las calles y plazas y numerar las manzanas y los nichos del cementerio; resultando que la más beneficiosa de todas era la de Don Vicente Sanchis, vecino de Valencia, quien se compromete a suministrar los primeros al precio de nueve reales cada uno, puestos aquí, los segundos, al de un real cincuenta céntimos y los terceros al de tres cuartillos de real, todos ellos de tinta negra y de primera clase; la corporación aceptó la propuesta de éste.

La documentació esmenta Vicente Sanchis, vecino de Valencia. Es tracta de Vicent Sanchis Enrique, hereu a través del seu pare Ramon Sanchis de l'antiga Fàbrica Reial del carrer Mossèn Femades que

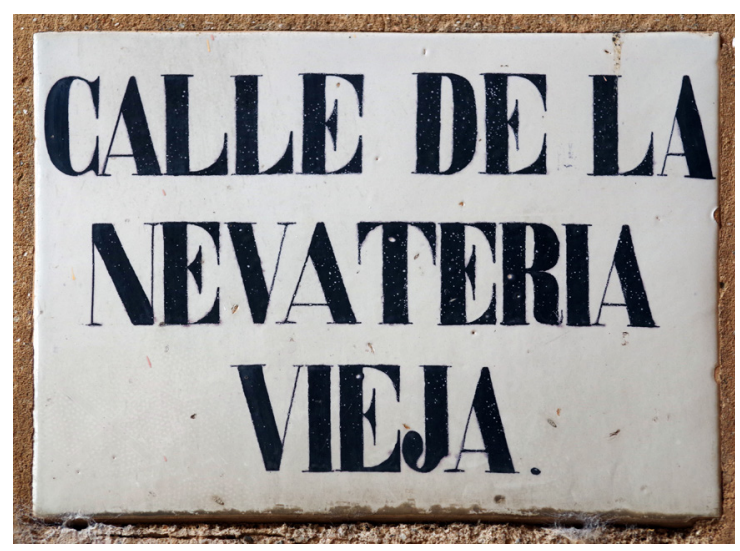

Fig 4. Carrer de la Nevateria vella, Xàtiva

havia pertangut a la família Disdier. Cal destacar que en la documentació de Xàtiva es fa menció expressa del color negre de bona qualitat que han de tenir els taulells (Cebrián \& Navarro 2009: 165). El mateix color amb què Ramon Sanchis havia retolat els carrers de València en 1837 i que havia presentat davant la comissió d'Indústria i Arts de la Reial Societat Econòmica d'Amics del País.

Abans de canviar els rètols dels carrers, l'Ajuntament de Xàtiva ja havia pres la decisió de renovar els números de les cases l’any 1859:

Pasando a tratar sobre la rectificación de la numeración de las casas prescrita por la Real Orden fecha 31 de Diciembre último y la circulares del Gobierno Civil de la Provincia, insertos en los boletines oficiales de los días once y catorce del corriente, el mismo señor Presidente espuso que la de esta Ciudad se encontraba tan defectuosa que en la mayor parte de las calles tenía que variarse desde el cuatro o cinco en adelante; y no pudiendo pasar de una casa a otra los azulejos que la contenían, puesto que para evitar la confusión que en los títulos de pertenencia causaría la desaparición de la numeración actual era preciso colocarlos en la parte interior de los edificios, resultaba que en cada calle se utilizarían solo cuatro o cinco números, y que por tan insignificante economía, ni había la conveniente uniformidad en aquellos, ni estarían colocados según el sistema moderno recomendado en la citada Real Orden, esto es, los pares a la derecha y los impares a la izquierda, partiendo del punto céntrico de la población. En 


\begin{abstract}
virtud de estas consideraciones, acordó el Ayuntamiento que se renovase por completo la numeración de las casas, arreglándose a dicho sistema, y que según lo prevenido en la última de las indicadas circulares, se satisficiesen de los fondos públicos el importe de los azulejos y gastos de su colocación, reintegrándose, terminada que fuera la de cada calle, de los dueños o inquilinos de los edificios situados en la misma.
\end{abstract}

S’hi conserva també l'expedient de 1860 relatiu a la col locació dels números on s'expressa que el contractista té l'obligació d'arrancar els números vells que queden i obrar-los en l'interior de les cases per poder identificar els edificis amb la numeració que constava en les escriptures de propietat. Com hem vist, els nous els obrarà a l'exterior. El 2 de juny s'esmenta que no s'ha pogut dur a terme el treball en el termini establert perquè no han arribat tots els taulells a l'Ajuntament des de la fàbrica. Finalment, el 19 de juliol, mes i mig després, ha finalitzat el procés urbà.

A continuació es fa la subhasta per a les cases de camp i els pobles annexos: Sorió i la Torre d'En Lloris. S'especifica que els números es posaran damunt de la porta d'entrada i centrats, i en l'interior els antics (si n'hi havia). Les cases de camp es divideixen en quatre sectors que hauran d'estar especificats als taulells en l'angle superior dret: N-E, S-E, S-O, N-O.

En total s'hi posaren 2.513 taulells de número de casa de realce o relieve, tal i com recull la documentació. D'aquest tipus de taulells encara se'n conserven alguns als carrers de Xàtiva. A les façanes de l'Hospital Vell troben els números, 1, 2 i 11; al carrer de la Corretgeria, a la casa cantonera amb la plaça de l'Arquebisbe Mayoral, el número 67; al carrer de Mossén Uriós el 14 i a la plaça de Roca el 17, per citar alguns exemples.

Per finalitzar amb la toponímia urbana, tenim notícia que Gastaldo, propietari de la fàbrica ubicada al carrer Nou de Pescadors de València, retolà carrers de Madrid en 1864 (Coll 2009: 237). El 19 de maig es comunica en premsa que la col locació de les noves senyalitzacions dels carrers està molt avançada. ${ }^{6}$ Encara resten al centre històric plaques com la de CALLE DEL CORREO, CALLE DE SANTA YSABEL, CALLE DE LAS HUERTAS o CALLE DE RAMALES, entre altres. Totes segueixen el model de les anteriors, és a dir, inscripció en negre sobre fons blanc. Però no tot el conjunt de les plaques valencianes a Madrid manté uniformitat de lletra. Dels exemples esmentats, els dos primers tenen caràcters més moderns de tipus egipci, amb remat més gros, mentre que els altres dos són idèntics als que produeix González Valls.

Les demarcacions judicials, inscrites sobre ceràmica, formen part de la retolació administrativa dels nostres pobles. S'obraven, com les anteriors, a una altura adequada dels murs. Així com els noms de carrer se situaven al començament de cada via, les plaques dels partits judicial es col locaven a l'entrada de les poblacions. Les que es conserven pertanyen al segle XIX, usen el color blau o negre sobre fons blanc i la tipologia de lletra és variada. Malgrat tractar-se de peces elaborades en el vuit-

6 La Correspondencia de España. 19/5/1864, núm. 2.175, p. 2. Llegim idèntica nota en el Diario oficial de avisos de Madrid. 20/5/1864, p. 4. 
Beatriu Navarro i Buenaventura \& Josep Lluís Cebrián i Molina. Retolació ceràmica urbana del segles XVIII i XIX: Les fàbriques de València

cents, no tots els rètols es fan sobre plaques. Molts encara fan servir taulells, plafons concretament, per a encabir la llegenda llarga completa. És el cas de CORTES DE ARENOSO, PARTIDO DE LUCENA, PROVINCIA DE CASTELLON, compost per dos taulells disposats horitzontalment i escrit en blau. També sobre taulells hi ha el de la VILLA DE NOVELDA CABEZA DE PARTIDO JUDICIAL. PROVINCIA DE ALICANTE, amb lletres negres i inclusió de subratllats, format per quatre taulells, dos sencers i dos mitjos. Cal advertir que les plaques presentaven dificultat de cocció per les dimensions. En forma de placa ceràmica trobem el de PUEBLO DE CELA D ${ }^{\mathrm{e}}$ NUNES. PARTIDO JU L DE COCENTAYNA. PROVINCIA D ${ }^{\mathrm{e}}$ ALICANTE, amb caràcters blaus, on no s'ha calculat bé la superfície ocupada per la inscripció i ha calgut introduir abreviatures.

\section{Rètols singulars}

La retolació urbana és bastant abundant. Hi trobem taulells indicant el Sitio de bando, com els que veiem a Borriana, Onda o Vila-real. Es marquen les fonts públiques com la FUENTE SANTA VECINAL $\mathrm{N}^{\circ} 1$ de Novetlè o la FUENTE SANTA VECINAL N ${ }^{\circ} 15$ de Xàtiva. Associat amb aquesta font de Xàtiva que hi hagué a la façana del Palau del carrer de l'Ardiaca, coneixem per fotografia antiga un taulell de multa on s'advertia: INCURRIRA EN LA MULTA DE 20 R. V. ${ }^{\mathrm{N}}$ EL QUE ENSUCIE O DETERIORE LAS FUENTES (Cebrián 2015: 189, 209).

Però no sempre es tracta de taulells relacionats amb l'Administració. Per exemple, a Llombai podem veure'n un que perpetua la memòria de l'inici d'una edificació: El dia 19 de Febrero de 1797 se principió ésta casa, y Real Fabrica de Albayalde. Idèntica intenció hi ha al de la façana de l'ermita dels Sants de Sueca: Se hiso en el año 1818, on ha quedat visible la pauta per a pintar la inscripció. Altres tenen caràcter commemoratiu com la de la Vilavella on s'al ludeix a l'arribada d'una relíquia de sant Sebastià el 1863 i s'acompanya d'una representació del sant pintada per Miquel Mollà (Cebrián \& Navarro 2012). També a la Vilavella, al seu museu, podem veure una indicació de Biblioteca. El rètol s'inscriu en un taulell de mostra fabricat a La Campana d'Onda entre 1850-1860 (Estall 2000: 87, inv. 504). La tipologia de lletra és bastant posterior, per tant segurament s'aprofitaria un taulell de disseny antic per a elaborar la retolació del lloc. Tot sense oblidar les peculiars marques de nivell de les riuades. A Cerdà a l'interior del palau es guarda un taulell orlat amb una corona vegetal de fulles ondulants on llegim El dia 4 de noviembre de 1864 llegó el agüa del rio Jucar hasta el punto señalado en el ladrillo. A Sumacàrcer, més senzilla que l'anterior, es mostra només la inscripció En el dia 4 de Noviembre del año 1864, subio elagua hasta aqui, amb una cursiva ben acurada i adornada.

Entre els incomptables rètols que encara romanen als nostres carrers volem destacar aquells que van més enllà del mer propòsit indicador, aquells que sobrepassen la finalitat principal i esdevenen obres pictòriques i artístiques.

Algunes senyalitzacions mostren tímidament una intenció ornamental afegint un marc mínimament

SCRIPTA, Revista internacional de literatura i cultura medieval i moderna, núm. 15 / juny 2020 / pp. 67-84 ISSN: 2340-4841 · doi:/ SCRIPTA.15.17303 
Beatriu Navarro i Buenaventura \& Josep Lluís Cebrián i Molina. Retolació ceràmica urbana del segles XVIII i XIX: Les fàbriques de València

elaborat. D'aquest tipus és la placa de la IGLESIA DE N ${ }^{\text {TRA }} S^{\text {RA }}$ DE LA ASUNCION [fig. 5] de Planes veiem veiem una sanefa perimetral tricolor elaborada a trepa on s'insinua un ombrejat. Idèntica, pel que fa a la vora i a la tipologia de lletra, és la retolació de la IGLESIA PARROQUIAL DEL SS ${ }^{\mathrm{MO}}$ CRISTO DE SAN SALVADOR de València. Possiblement, totes dues eixiren dels forns de González Valls. Aquests marcs foren freqüents en els plafons devocionals pintats a partir dels anys 60 del segle XIX, per tant podem donar a les plaques una cronologia propera.

En la porta de l'Ajuntament de la Pobla d'Arenós, inserit en la clau de l'arc, trobem el taulell de numeració $N u^{\circ} 1^{\circ}$. Les lletres negres amb una ornamentada cal ligrafia flanquegen un oval que conte l'escut del poble: sobre un terreny amb petits matolls s'alça una torre quadrada bastida amb carreus, tot resolt amb delicadesa. La tipologia curvilínia de l'1 l'hem vista als taulells de numeració de realce o relleu de les cases de Xàtiva col locats el 1860, datació que es correspon amb els postulats pictòrics de l'exemplar de la Pobla d'Arenós.

La Casa badia era un altre dels edificis que acollia als seus murs un rètol de localització. Al taulell de Vilallonga, entre les paraules CASA i ABADIA, en capitals blaves, es pintà un bonet negre sense

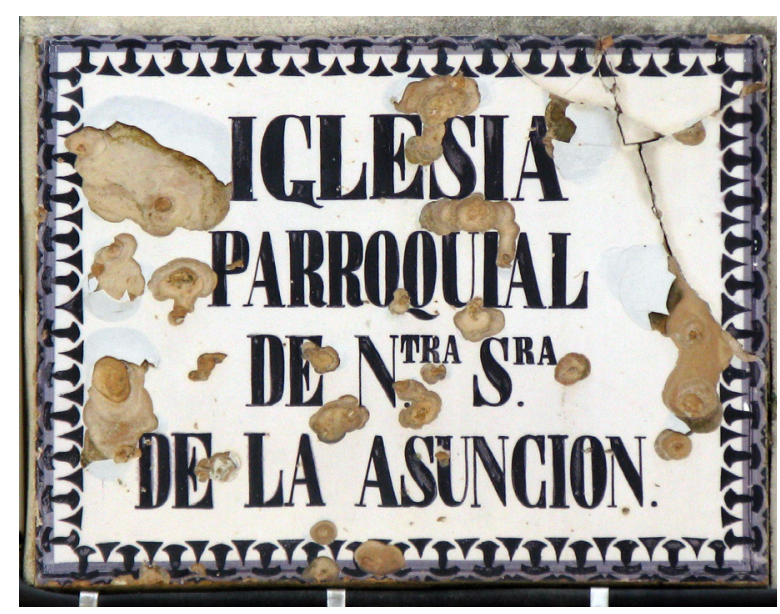

Fig 5. Església parroquial de l'Assumpció, Planes



Fig 6. Casa badia, Ontinyent

més pretensions que mostrar la silueta de l'objecte. A Ontinyent, en canvi, trobem una placa amb una representació il lusionista datable a mitjan segle XIX [fig. 6]. Sobre un altar de marbre se situa un missal amb tancaments metàl lics i cintes de registre, i sobre el llibre, un bonet, tot recorregut per una garlanda vegetal. Al frontal de l'ara es llegeix en majúscules ombrejades en blau ABADIA.

A la façana del convent de Santa Úrsula de València es conserva un plafó de 12 taulells amb especejament de $4 \times 3$ amb la inscripció CONVENTO DE S ${ }^{\text {ta }}$ URSULA sobre la qual s'ha representat l'emblema del cenobi [fig. 7]. Situada vora les Torres de Quart, l'antiga Casa de les Penedides de l'orde del Carme fou erigida en convent d'agustines amb l'advocació de Santa Úrsula en 1605 
Beatriu Navarro i Buenaventura \& Josep Lluís Cebrián i Molina. Retolació ceràmica urbana del segles XVIII i XIX: Les fàbriques de València

sota l'auspici de Joan de Ribera (Vizcaino 2007: 86, 88). Una cartel la geminada daurada d'extrems enrotllats recull dos ovals. Un d'ells conté l'escut del Patriarca amb l'eucaristia, la creu de doble travesser i el capell cardenalici. En l'altre, el cor flamejant travessat per sagetes de sant Agustí. Tot el conjunt es remata amb una garlanda de llorer, i a la part superior hi ha els atributs iconogràfics de la santa titular del convent: la palma del martiri i la bandera.

Pels seus trets pictòrics el plafó es pot datar entre 18601 1880. La inscripció amb capitals properes a les tipografies egípcies encara manté per a les volades l'estil de lletra amb modulacions. Estem en un moment en què el nou disseny de retolacions no s'ha assentat definitivament. La intensitat de policromia, amb predomini del groc, el verd oliva i el morat, l'abundància de raspats per a proporcionar efecte de lluentor als objectes, els traços del tèxtil o l'ús del

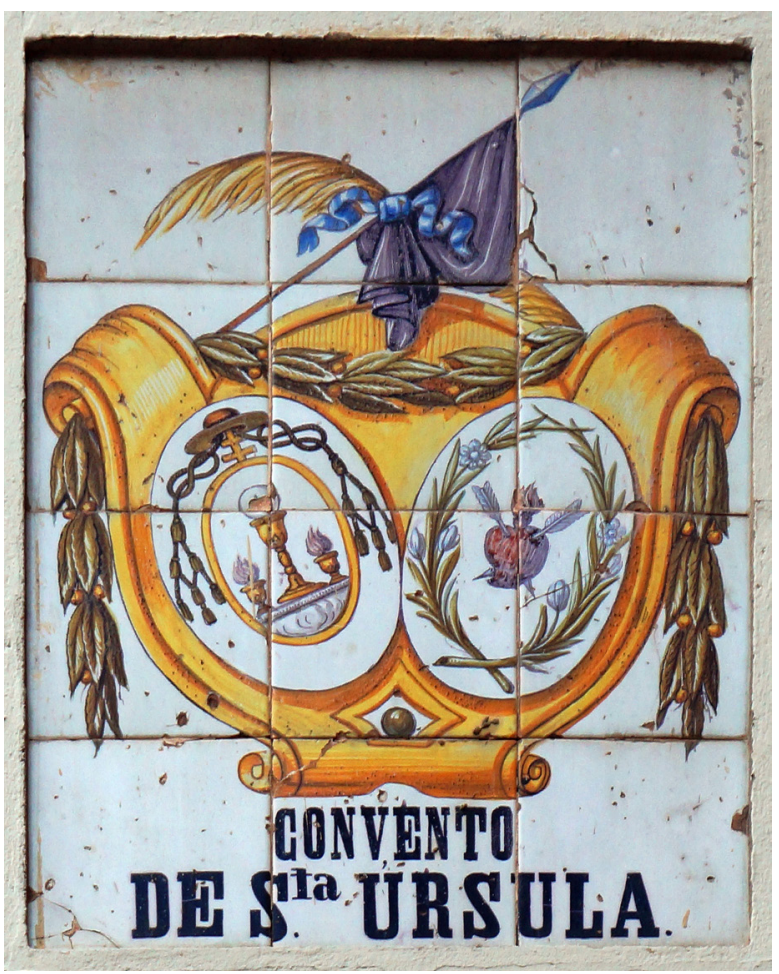

Fig 7. Convent de Santa Úrsula, València perfilat negre apunten vers la possible autoria del Mestre de Santa Anna.

El pintor, de nom desconegut, rep aquesta denominació pel plafó devocional dedicat a la santa que hi ha al Mas del Racó de Santa Anna d'Alcoi. Té nombrosa obra datada entre 1865 i 1880 i es mou entre dos registres pictòrics: l'estil revival i el pictoricisme, segons el gènere que practique. Desenvolupa la seua activitat als obradors de la ciutat de València, encara que durant l'última etapa apareix vinculat a la fàbrica d'Onofre Valldecabres de Quart de Poblet (Navarro \& Cebrián 2019: 64-65).

Analogies evidents amb el plafó de les agustines trobem al rètol de la YGLESIA DEL REAL CONVENTO DE RELIGIOSAS FRANCISCANAS DE LA PURIDAD Y SAN JAYME de València [fig. 8]. És un panell format per 14 taulells, amb la particularitat de presentar retallada la part superior en forma mixtilínia, fet inusual en la taulelleria valenciana. Com l'anterior, dos ovals contenen els símbols relatius al convent. El bordó, el capell i la petxina pintats sobre els pals d'Aragó al ludeixen a sant Jaume; els braços de Crist i sant Francesc creuats sobre la creu són l'emblema franciscà. Dalt, l'anagrama coronat de Maria sobre el creixent lunar. Es tracta igualment d'una obra atribuïble al Mestre de Santa Anna. 


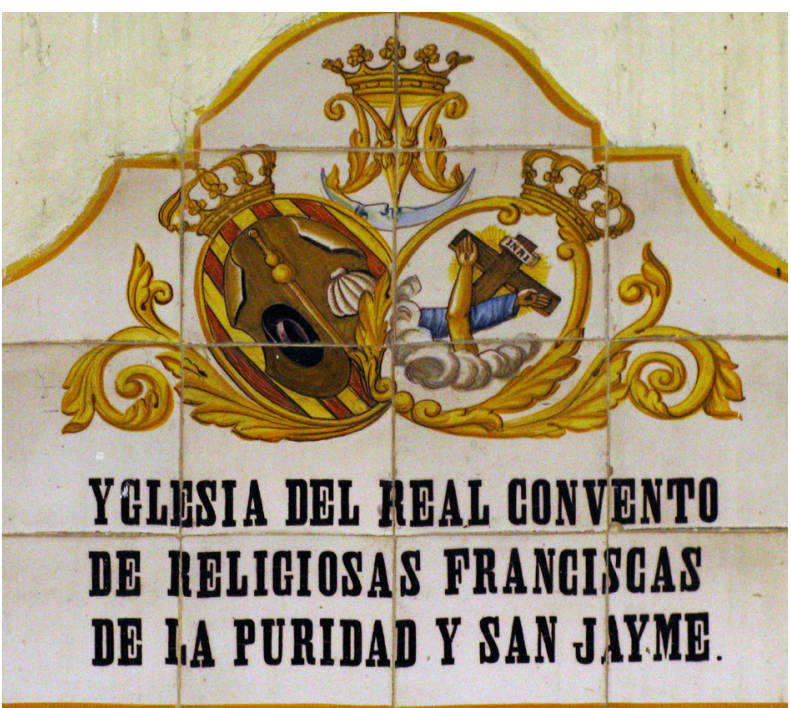

Per a retolar el carrer de Santa Rita d'Alzira s’aprofità un plafó de la devoció pintat vers 1780 Fig 8. Convent de la Puritat, València

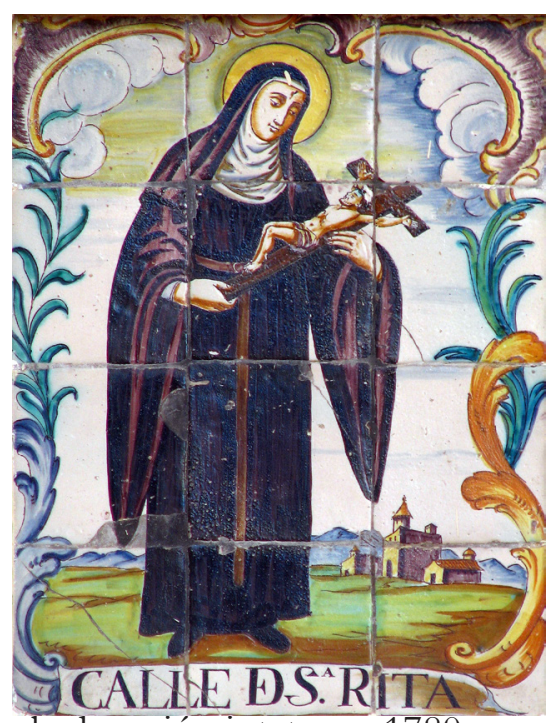

Fig 9. Carrer de Santa Rita, Alzira

Està compost per 12 taulells amb especejament de $4 \times 3$ [fig. 9]. Es representa la santa amb els seus atributs iconogràfics: l'hàbit negre dels agustins, amb cinturó, el crucifix i l'espina al front. La decoració de rocalls i branques que l'envolta té com a base un filacteri amb la indicació CALLE DE S ${ }^{A}$ RITA. És per tant un plafó que a la funció devocional afegeix el nom del carrer, la qual cosa implicaria que fou un encàrrec del veïnat.

Al Vilar de l'Arquebisbe trobem un plafó dedicat a la Mare de Déu de la Pau. Està signat per Joan Bru i cuit a les Reials Fàbriques de València vers 1800. De Bru, pintor excel lent nascut en 1773, només coneixem la seua activitat fins 1809. És, junt a Josep Sanchis, l’iniciador del pictoricisme academicista, cultivant cert idealisme en la seua obra front el naturalisme de Sanchis (Navarro \& Cebrián 2019: 54-56).

A la part inferior del plafó llegim La Virgen de la Pas del Villar. Correo per a senyalar el lloc de partida de la diligència amb destinació a la capital (Segura 1995: 34-35). Es tracta d'un plafó devocional com tants altres sota una advocació mariana, però que ha estat aprofitat com a retolació urbana per tal d'indicar un lloc concret d'emplaçament. Es tracta d'un cas semblant a l'anterior d'Alzira.

\section{Plaques d'assegurances d'incendi}

Malgrat no tractar-se de senyalitzacions oficials, analitzem breument les plaques ceràmiques de les Companyies d'assegurança. N'han sobreviscut un nombre considerable de manera que actualment tenen una presència important, tanta com les indicacions administratives, als nuclis antics de les nostres ciutats i pobles. 
Aquestes plaques s'obraven a la façana de les cases i en cas de la destrucció provocada per incendi constituien una prova de la relació de l'immoble amb l'empresa asseguradora, car es tractava d'un material resistent al foc (Cebrián \& Navarro 2009: 169), ben al contrari que la pòlissa de paper.

La Companyia més coneguda, potser perquè cobreix un àmbit territorial més extens, era la Sociedad de Seguros Mutuos de Valencia y su Provincia. Les famoses plaques de l'ASEGURADA tenen format rectangular vertical $\mathrm{i}$ un disseny singular que identifica clarament la marca [fig. 10]. Sobre una illa suspesa en l'aire, un edifici amb torre cantonera s'incendia, amb flames sortint de les finestres i columnes de fum. Dalt, el rètol Asegurada en forma d'arc i lletres negres majúscules. Amb el temps s’inclourà en la base dels caràcters una pinzellada de color marró, aconseguint

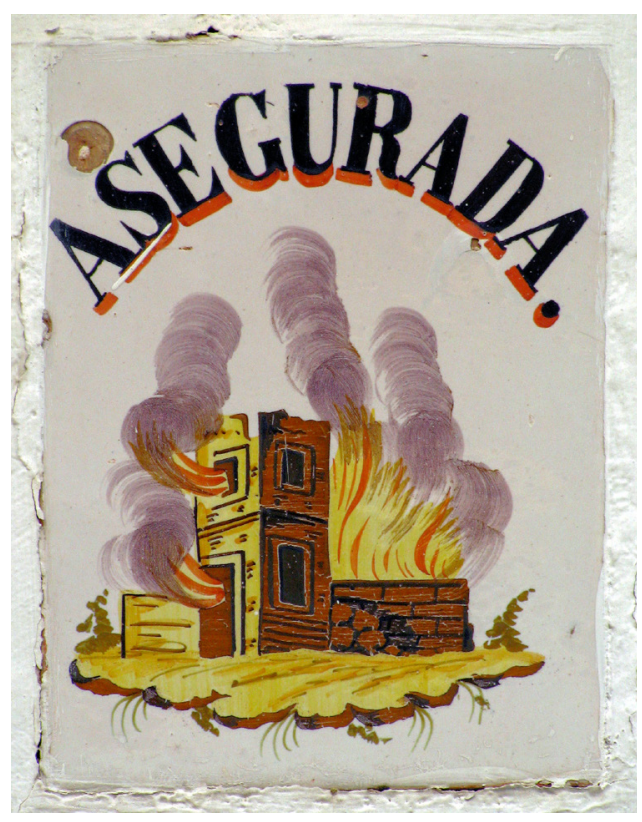

Fig 10. Assegurada d'incendis, Alboraia així sensació d'ombrejat i volum, i s'usaran trepes per a acolorir la casa. Ja en el segle XX es canvien els colors i les plaques, ara horitzontals, i es fan a motle.

La Societat es fundà en 1849 i tenia la Secretaria general al carrer de Cavallers de València, segons els anuncis que publicava en premsa on incloïa el dibuix de la construcció en flames que es veu a les ceràmiques (Bolinches 1991, I: 304-305). Per tant, totes les plaques de l'Assegurada que veiem a les façanes dels edificis són posteriors a aquesta data.

Cada empresa feia servir un disseny específic que la distingia de la resta. La majoria eren d'abast local. A Xàtiva la companyia d'assegurances era La Setabense, constituïda l'any 1859 (Cebrián 2015: 198-199). Una societat que feia servir un taulell molt senzill, sense cap dibuix al legòric o escena pictòrica en color, de manera que s'abaratia la despesa d'elaboració. De la mateixa manera que les plaques anteriors de l'Asegurada, cal datar aquestes a partir de l'any de fundació, de 1859. A la façana de moltes cases de la ciutat es conserva la placa ceràmica rectangular disposada horitzontalment amb la inscripció Asegurada de incendios / por la / Setabense. Tot en majúscula negra, la primera línea arquejada presenta les lletres més petites. L'esquema de les plaques no varia, però es detecten canvis en la cal ligrafia conforme avança el temps. L'esmalt, al principi d'un blanc molt consistent, anirà perdent opacitat.

Ferrándiz i Carbonell es féu ressò en la premsa de l'aprovació dels estatuts de l'asseguradora local i ens facilita alguns detalls interessants als seus annals de Xàtiva (Ferrándiz 2016: 207): 
Beatriu Navarro i Buenaventura \& Josep Lluís Cebrián i Molina. Retolació ceràmica urbana del segles XVIII i XIX: Les fàbriques de València

\begin{abstract}
Reuniéronse estos bajo la presidencia de la autoridad local y fundaron una sociedad de seguros mutuos contra incendios, redactando al efecto sus estatutos, y comprendiendo sólo sus beneficios a los radicados dentro del casco de la Ciudad (artículo $2^{\circ}$ ), cuyos estatutos fueron aprovados en 16 de julio de este año 1859, titulándose la sociedad «La Setabense». En 28 de junio de 1860 publiqué en el diario mercantil de Valencia un remitido sobre el estado floreciente que se hallaba la Sociedad, en vista de los libros, asientos y registros que me franquearon su presidente D. José Ferrer y secretario D. José Matute, y me admiré del progreso que en tan poco tiempo había experimentado, contando a la fecha un capital asegurado de cinco millones trescientos treinta y cinco mil ochocientos cincuenta reales, siendo los socios asegurados en número de 147. Se estaba montando una sección de bomberos en número de 24 , todos artistas e industriales, al mando de un maestro de obra y un sargento para dirigir los trabajos en el momento de un incendio, los cuales debían llevar una blusa azul, casco de suela y cinturón de correa, con su porta hacha, polainas prolongadas sobre las rodillas, y armados de picos, hacha y demás útiles de la institución, con una bomba auxiliar traída de París, montada sobre un carrito para su fácil traslación que costó 5.500 r. v. El uniforme referido cuyo figurín vi, causa muy buen efecto.
\end{abstract}

Existien altres companyies locals d'assegurances contra incendis de les quals trobem taulells als carrers d'Alberic, Carlet, Guadassuar -assegurada por la Fraternidad-, Alzira -la Sucro-, entre altres. Els taulells pertanyen ja al segle XX i estan pintats amb trepes. Entrat el segle XX la ceràmica seria substituïda per plaques de llauna com les de les empreses Norwich Union o La Catalana. En el cas de La Catalana, les plaques metàl liques eren en color, perquè algunes conservades en interiors, a la jàssena de la planta baixa, mantenen la policromia.

Aquesta vessant tipològica de la taulelleria, les retolacions urbanes, que gaudiren d'una producció extensa al llarg dels segles XVIII i XIX, en consonància amb l'eclosió artística i productiva de la taulelleria valenciana, s'anirà abandonant a poc a poc. Al segle XX s'imposaran retolacions elaborades amb nous materials, més econòmics, al temps que els gusts i modes es renovaran. Els noms dels carrers també seran substituits al darrer terç del segle XX per plaques metàl liques de color blau a imitació de les plaques ceràmiques de la primera meitat del segle XX. 
Beatriu Navarro i Buenaventura \& Josep Lluís Cebrián i Molina. Retolació ceràmica urbana del segles XVIII i XIX: Les fàbriques de València

\section{Bibliografia}

Bolinches Molina, J. (1991) La azulejería valenciana del s. XIX, Tesi doctoral inèdita, València, UPV.

Cabot Estarellas, J. \& Mulet, B. (1990) Rajoletes policromes a Mallorca, Palma de Mallorca, Miramar.

Cebrián i Molina, J. Ll. (2005) Quart de Poblet: Art i patrimoni, Xàtiva, Ulleye.

. (2014) «El Pintor de la Conquesta i la Reial fabrica de taulells de Valencia», Recerques del Musen d'Alcoi, 22-23, pp. 107-120.

(2015) «Taulelleria històrica als carrers de Xàtiva», dins Navarro i Buenaventura, B. (ed.) Notes i pinzellades al voltant de Xàtiva. Actes de les VI Jornades d'Art i Història a Xàtiva. Xàtiva 4 , 5 i 6 d'agost de 2014, Xàtiva, Ulleye, pp. 193-209.

Cebrián i Molina, J. Ll. \& Navarro i Buenaventura, B. (2009) Pintura ceràmica a Xàtiva. Plafons devocionals, läpides funeràries i taulells de mostra dels segles XVIII i XIX, Xàtiva, Ajuntament de Xàtiva.

. (2012) «Els plafons devocionals de M. Mollà i Manuel Garcés a Jesús Pobre». Aguaits, 31, pp. 131-147.

- (2014) Francesc Dasí i la taulelleria valenciana del segle XIX, Xàtiva, Ulleye.

Coll Conesa, J. (2009) La cerámica valenciana. Apuntes para una sintesis, València, AVEC.

Estall i Poles, V. (2000) Catálogo de la colección de azulejos de serie del siglo XIX, Onda, Museu del Taulell.

Faus y Faus, J. (1983) Páginas de la historia de Segorbe: 1850-1900, València, Marí Montañana.

Ferrándiz i Carbonell, J. P. (2016) Anales o memorias de Játiva (1833-1861), Ms. ed. G. Ramírez Aledón, transcr. B. Navarro i Buenaventura, Xàtiva, Ulleye.

Gironés Sarrió, I. \& Guerola Blay, V. (2016) La taulelleria valenciana dels segles XVII, XVIII i XIX a la col lecció de la Fundació la Fontana, València, Alfons el Magnànim.

Madoz, P. (1849) Diccionario geográfico-estadístico-histórico de España y sus posesiones de ultramar, vol. XV, Madrid, Est. Tip. P. Madoz y L. Sagasti.

Mateo, V. (1998) Cerámica y bierro. Descubrir el centro bistórico, València, Conselleria d’Obres Públiques, Urbanisme i Transports.

Navarro i Buenaventura, B. \& Cebrián i Molina, J. Ll. (2019) «Pintors dels segles XVIII i XIX», dins Taulelleria devocional d'Alcoi (segles XVIII i XIX), Alcoi, Ajuntament d'Alcoi, pp. 49-71.

Olucha Montins, F. (2020) Guia de la secció de Ceràmica del Museu de Belles Arts de Castelló, Castelló, Diputació de Castelló. 
Beatriu Navarro i Buenaventura \& Josep Lluís Cebrián i Molina. Retolació ceràmica urbana del segles XVIII i XIX: Les fàbriques de València

Ray, A. (2000) Spanish Pottery 1248-1898. With a catalogue of the collection in the Victoria and Albert Museum, Londres, V \& A Publications.

Segura Estevan, C. (1995) Paneles devocionales y cruces en el Villar del Arzobispo, Vilar de l'Arquebisbe, Ajuntament del Vilar de l'Arquebisbe.

Vizcaíno Martí, M. E. (2007) Composiciones cerámicas valencianas del siglo XVIII, València, Ajuntament de València.

Zaforteza y Musoles, D. (1956) «La azulejería valenciana en la rotulación de la ciudad de Mallorca», Anales del Centro de Cultura Valenciana, 38, pp. 197-206.

SCRIPTA, Revista internacional de literatura i cultura medieval $i$ moderna, núm. 15 / juny 2020 / pp. 67-84 